DOI: https://doi.org/10.24127/ajpm.v9i3.2902

\title{
DEVELOPMENT OF MATHEMATICS TEACHING MATERIALS BASED ON SCIENTIFIC APPROACH FOR MATHEMATICS LEARNING
}

\author{
Heni Pujiastuti ${ }^{*}$, Rudi Haryadi ${ }^{2}$, Faizal Ridwan ${ }^{3}$ \\ $1^{*}, 2,3$ Universitas Sultan Ageng Tirtayasa, Banten, Indonesia \\ *Corresponding author. Jalan Raya Jakarta KM.04, 42111, Banten, Indonesia. \\ E-mail: $\quad$ henipujiastuti@untirta.ac.id ${ }^{\left.l^{*}\right)}$

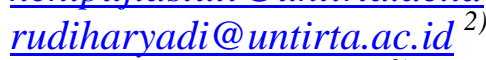 \\ faizalrdw@gmail.com ${ }^{3)}$
}

Received 01 July 2020; Received in revised form 23 September 2020; Accepted 26 September 2020

\begin{abstract}
This study aims to develop mathematics learning based on a scientific approach to support learning mathematics in understanding mathematical concepts. This research method is to use research and development with 4D models. The 4D model consists of four steps: determining, designing, developing, and disseminating. The subjects of this study were junior high school students with an average age of 12 years. The instrument used is the feasibility aspect of the learning media. The technique used is seen from the feasibility of teaching material media. The results showed that the visual element was $87.50 \%$, which means that this mathematics teaching material has an excellent visualization. The part of software engineering is $94.44 \%$, which means that mathematics teaching materials are elementary to use and access. The implementation aspect is $83.33 \%$, which means that mathematics teaching materials can be alternative support for increasing student motivation and self-regulation. The result for content accuracy is $87.5 \%$, which means that mathematics teaching materials have perfect content accuracy. Then for the presentation aspect is $70.83 \%$ included in both categories. The evaluation aspect is $77.78 \%$, which means the evaluation instruments in mathematics teaching materials are varied and quite tricky. The language used is $91.67 \%$, which means the language used in mathematics teaching materials is very communicative, easy to understand, and students' cognitive development. The teaching material is suitable for mathematics learning for junior high school students based on the results obtained.
\end{abstract}

Keywords: Mathematics learning; mathematics teaching materials; scientific approach.

This is an open access article under the Creative Commons Attribution 4.0 International License

\section{INTRODUCTION}

Mathematical learning is a process of student interaction with educators who learn about structured knowledge where nature and theory are deductive based on the elements that are defined or not defined truths that use the language of symbols of various ideas carefully, clearly, and accurately (Pujiastuti et al., 2020). By solving mathematical problems, students learn to use mathematical concepts. This reasoning skill makes mathematics in school so important (Zuin et al., 2018).
Not every subject uses algebra and trigonometry, but every issue needs reasoning skills to understand events and critical thinking patterns before deciding (Solomon \& Croft, 2015).

These days, critical thinking, problem-solving, and decision making are 21st-century skills et al., 2017). Society demands all of them everywhere to make decisions and act accordingly with their natural environment and social condition. Coincidentally, these skills are parts of the $21^{\text {st }}$-century mathematics learning 
experience (Mcgrath \& Fischetti, 2019). Learning must be focused on conceptual understanding to improve math skills in the classroom (Zaslavsky, 2019).

Conceptual understanding helps students avoid many critical errors in solving problems, particularly errors of magnitude (Wessman, 2019). But in some cases, teachers only tell the students to memorize the formula or concept, which leads to rote learning (Pujiastuti et al., 2020). Such a surface strategy would be counterproductive in cases where one learns by working through novel problems, applying examples to new situations where deep conceptual understanding is required (Zaslavsky, 2019).

Students need conceptual understanding to achieve higher skills, and the necessary skills are requirements to understand more complex concepts (Pujiastuti et al., 2019). Conceptual understanding frequently results in students having less to learn because they can see the more profound similarities between superficially unrelated situations (Mason, 2019). As such, the habit of teaching to understand the concepts should be cultivated since primary school (Simon, 2018). By the time the students in high school or even college, they would be used to understand the logic behind mathematical concepts, which could yield an ability to apply those concepts into both mathematical and real-life problems (Shepherd \& Sande, 2014).

Several studies have shown us ways to improve students' conceptual understanding through teaching models and the use of the medium (Pujiastuti \& Haryadi, 2020). In Indonesia, learning through a scientific approach in the mathematics classroom, as recommended by The Ministry of
Education and Culture, has improved students' conceptual understanding in secondary and higher education (Pujiastuti, et al., 2020). The same result happens in studies on using ICT as a medium in mathematics learning (Simonova \& Poulova, 2017). As an integrated component of teaching and learning, ICT allows learning experiences that are innovative, accelerated, enriched, and deepens skills acquisition (Chakraborty, 2008). The teacher can mediate students' mathematical concepts through manipulative applications and documents (Pujiastuti \& Fitriah, 2019).

The utilization of ICT in mathematics learning comes in many forms (Lubis, 2018). E-learning can optimize blended learning designs and pure online math courses (Simonova \& Poulova, 2017). They are learning content that students and teachers can download and learn before meeting face-to-face in the classroom (Humienny \& Berta, 2015). Thus, discussions, simulations, or practices will use face-to-face meetings. (Te Pas et al., 2015).

The learning process has emerged as an innovation in fun-learning design for students (Su, 2017). It allows users to engage themselves in daily activities and workflow with rewarding, fun, and memorable experience (Soboleva, Galimova, \& Maydangalieva, 2018). Users feel that they have achieved something and become addicted to their daily activities (Fan \& Xiao, 2015).

In an educational context, the game's power lies in its ability to motivate people, especially adolescents, to want to learn, keep learning, know what they are remembering, and want to learn more (Su \& Hsaio, 2015). The game will take students to go beyond rote learning (Lin, 2017). Their 
DOI: https://doi.org/10.24127/ajpm.v9i3.2902

engagement in game-like mathematical activities will promote mathematical thinking, including conceptual understanding (Su \& Hsaio, 2015). Thus, investment in the game of mathematics learning is worth making (Teng et al., 2017).

In this study, try to game mathematics learning based on a scientific approach by developing a game. The game runs on Android-based smartphones to facilitate students' learning anywhere and anytime. The subject is Number Patterns, Sequences, and Series.

\section{RESEARCH METHOD}

In this study, Research and Development with the 4D model were used (Borg \& Gall, 2003). The 4D development model consists of 4 main stages: Define, Design, Develop, and Disseminate. It can be seen in Figure 1.

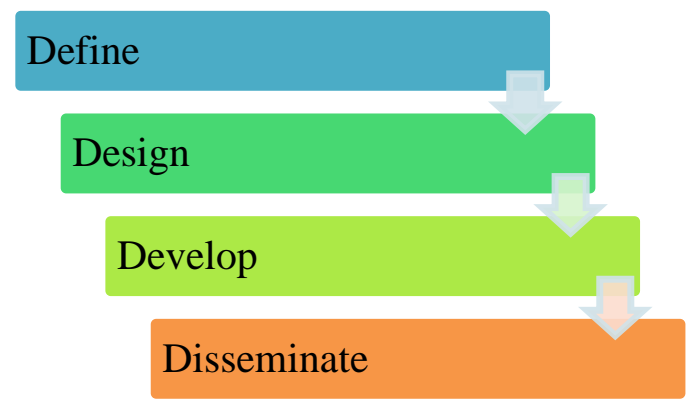

Figure 1. 4D Models

This study involved subjects, namely junior high school students, with an average age of 12 years. Instrument in this research and development is validation sheets for material and media experts as the feasibility of the teaching material media . The data analysis technique uses the calculation of the feasibility of media experts and student responses after using the teaching material media.

\section{RESULT AND DISCUSSION}

Based on a scientific approach to Class 9, mathematical teaching materials are a game application to facilitate student mathematics learning. Based on Class 9 scientific approach, mathematics teaching materials are a game application to facilitate students' mathematics learning. Math teaching materials use an android platform that allows users to access them on student smartphones. One of the fundamental aspects of applying mathematics teaching materials is the scientific approach, which is observing, asking questions, experimenting, and reasoning. The display of advanced mathematics teaching materials is in Figure 2 .

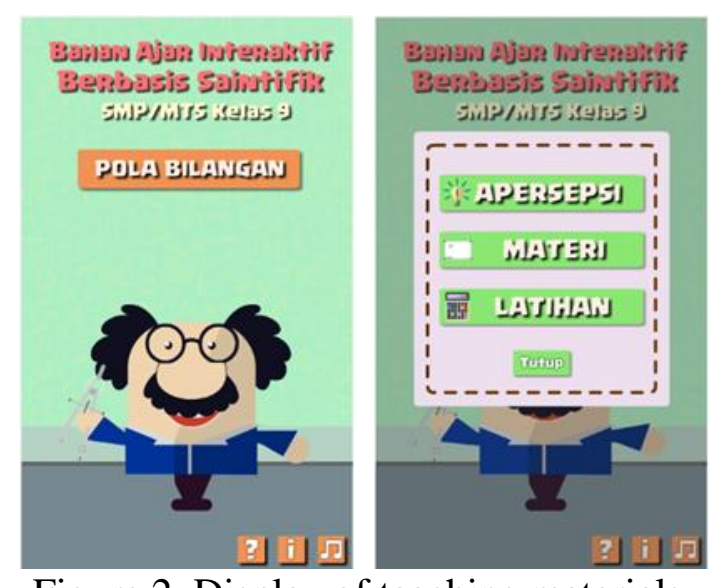

Figure 2. Display of teaching materials mathematics with a scientific approach

Figure 2 shows the display menu of mathematics teaching materials. Students then choose where they begin to learn perceptions and material. Selecting apperception will display an apperception page consisting of videos related to the subject. The video shows what events the Fibonacci sequence exists in nature. It functions as an effort to motivate students by connecting mathematics and nature. 
DOI: https://doi.org/10.24127/ajpm.v9i3.2902

\section{Observing}

When students try to understand mathematical concepts, they need to observe related events. This event can be in the form of daily life. Learning with this mathematics teaching material starts with watching and finding patterns of events (can be seen in Figure $3)$.

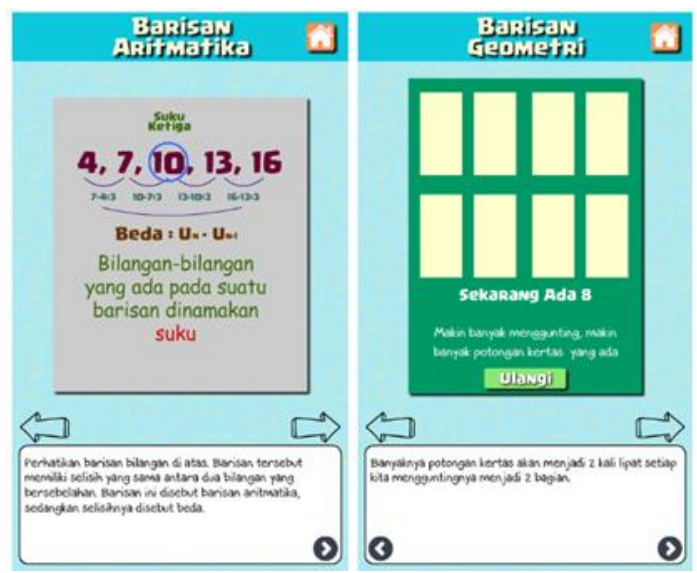

Figure 3. Observing stage in teaching materials mathematic with a scientific approach

\section{Questioning}

Questions are an integral part of learning or thinking that starts with questioning something. In understanding concepts, students realize that they still do not understand what is being taught and try to assimilate and accommodate new ideas into their cognitive schemes. It also helps them develop critical thinking and problemsolving skills. With this scientific approach, mathematical teaching materials can facilitate this by letting students create their questions to answer themselves. The sample of questioning part can be seen in Figure 4.

\section{Reasoning}

Students can answer the questions they made earlier with reasoning related to arithmetic series and geometry series in this learning process. Students do this before giving formulas to encourage the development of their conceptual understanding rather than procedural ones (Figure 5).
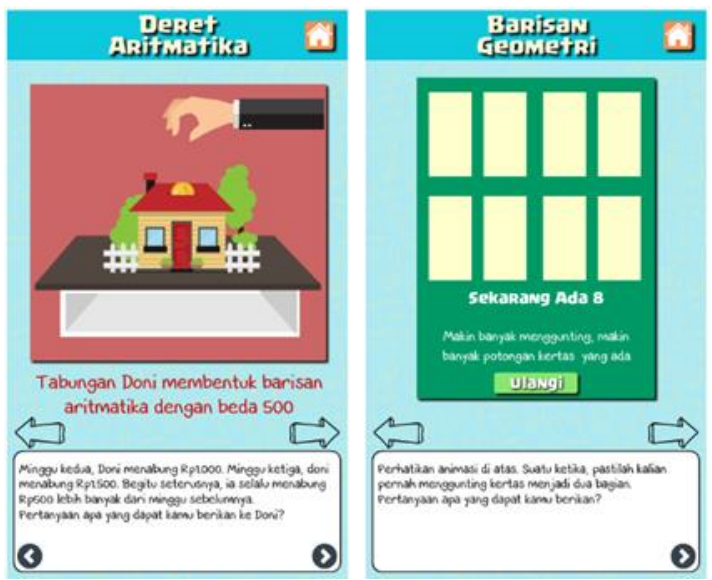

Figure 4. Questioning stage in teaching materials mathematic with a scientific approach

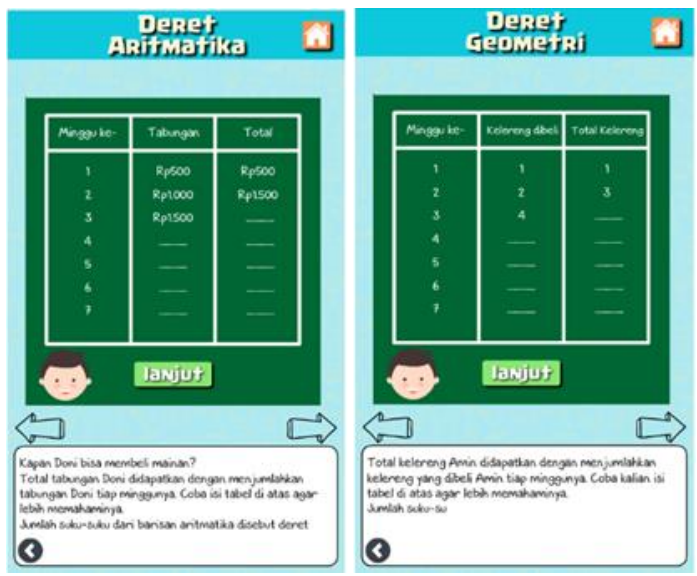

Figure 5. Reasoning stage in teaching materials mathematic with a scientific approach

\section{Experimenting}

Students solve problems by comparing two answers; one with the basic concept of the series and one with the series formula. The goal is students must be able to prove and understand about how to solve the problem by using one of the concepts on series. Experimenting part can be seen in Figure 6. 
DOI: https://doi.org/10.24127/ajpm.v9i3.2902

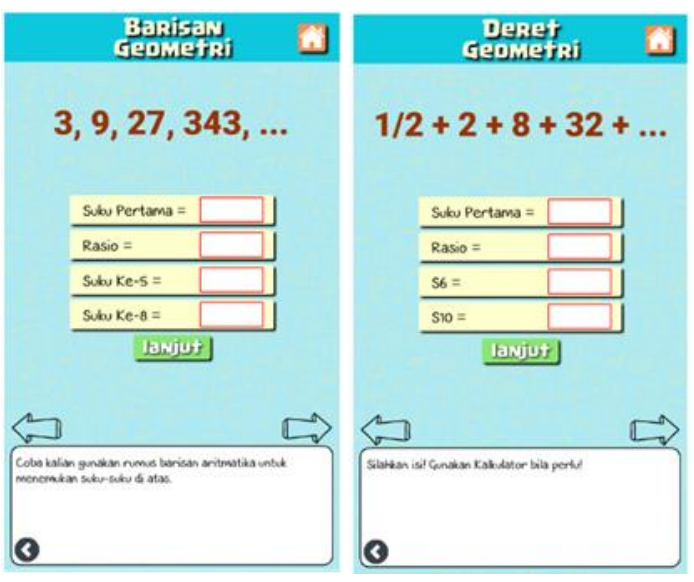

Figure 6. Experimenting stage in teaching materials mathematic with a scientific approach

\section{Evaluation}

In the learning process, using mathematics teaching materials is not about how students learn to use games, but about integrating game elements into learning activities. Students do not play the whole game from beginning to finish. Students participate in activities that include video elements or mobile games such as producing points, overcoming challenges, or receiving badges to complete assignments. Features of this game appear as external factors to motivate student involvement in learning. However, it is essential to moderate how many elements of the game to make students understand that they are learning rather than playing games.

Game elements integrate into the evaluation page, reasoning stage, and experiment stage. In experimenting and reasoning, students face the challenge of completing a task before proceeding to the next explanation. On the evaluation page, there is one task per character. After the student completes the assignment, the next one will appear, and the score will save so that students know the progress they are making. Figure 7 shows the evaluation stage.

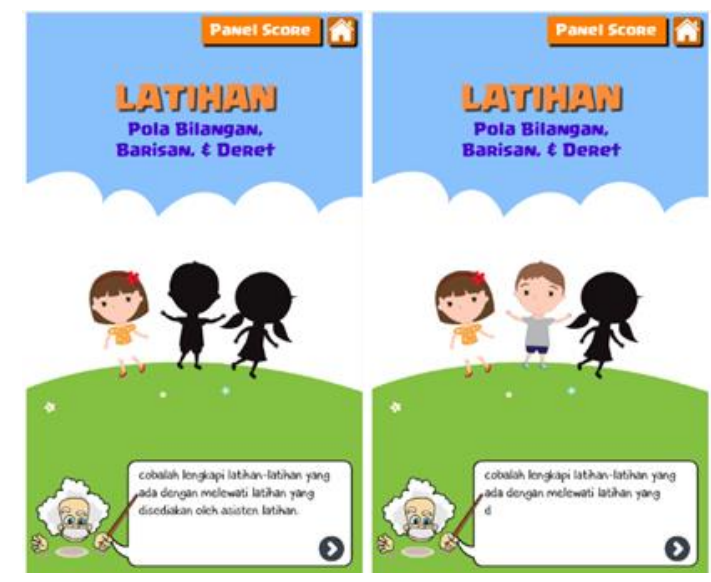

Figure 7. Evaluation stage in teaching materials mathematic with a scientific approach

After build the media, the nest is about validity of media. Furthermore, the validity results are in Figures 8 and 9 .

\section{Learning Media Experts Validation}

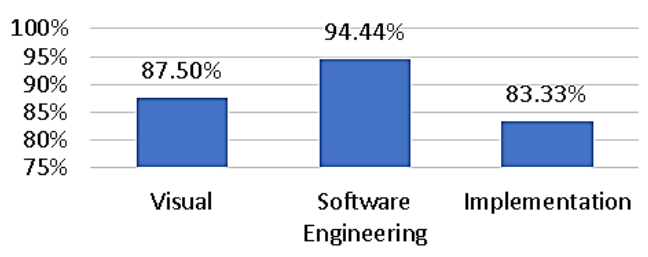

Figure 8. Learning media expert evaluation

Content Experts Validation

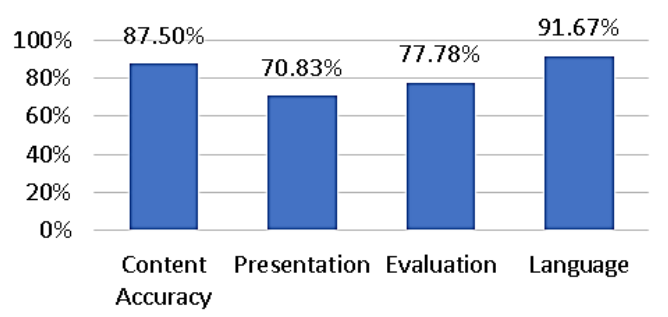

Figure 9. Content expert validation

Figure 8 that the visual aspect's average value is $87.50 \%$, which means it has an excellent visualization. The average value for the software engineering aspect is $94.44 \%$, which means it is straightforward to use and 
DOI: https://doi.org/10.24127/ajpm.v9i3.2902

access. The average cost for the implementation aspect is $83.33 \%$, which means it can be alternative support for increasing student motivation and selfregulation.

Furthermore, Figure 9 shows that the average score for content accuracy is $87.5 \%$, which means excellent content accuracy. The average value for the presentation aspect is 70.83\%. Even though it needs a little revision, experts have considered teaching materials' media presentation appropriate. The evaluation aspect's average value is $77.78 \%$, which means that the evaluation instruments are varied and quite tricky. The average cost for language elements is $91.67 \%$, which means the language used is very communicative, easy to understand, and following students' cognitive development.

The current pace of technological advancement mainly affects our society, including in the educational context. Combined with the desire to continue to make improvements, many education practitioners use technology in learning. With students' engagement considered the most critical factor in effective mathematics teaching, the game emerges as a new method to achieve a better educational result. The game creates exciting and fun ways to engage students in learning mathematics, sometimes even without realizing it (Teng et al., 2017).

Several studies report how engaging students in-game learning improves students' motivation summarized these reports, finding that the inclusion of game elements resulted in positive effects on the students (Psycharis \& Kotzampasaki, 2019). Arguably, the utilization of game elements in learning can be considered an extrinsic stimulant to motivate students. However, one must think that extrinsic motivators' long-term exposure harms students, specifically to lowperforming students or those who are not intrinsically motivated (Lee, 2017).

Among other things improved as a result of the game, learning is student' engagement in the mathematics classroom. Integrating game elements in education creates an environment full of enjoyment for students, motivating them to engage in the school. Mathematics learning is tedious and complicated, as many believe. Instead of attending a regular classroom, our study reports students felt that they were playing a game. As we know, addiction to games encourages people to play it more. Therefore, game learning opens the possibility for re-engagement to occur inside and outside the classroom. Re-engagement increases the exposure and practice of mathematical tasks by students (Saritepeci, 2019).

This study found that using teaching materials mathematics as a game instrument helps middle school students grasp the mathematical concept. Other studies report that game learning intervention produces improvements in student mathematics test scores and math fluency. Using a game to improve specific mathematical skills is something to look forward to and needs further research (Sriklaub \& Wongwanich, 2014).

However, dependency only on game instruments and eliminating other pedagogical practices in learning may not be the best option. However, this study does not compare the game-only and game-with-discussion classes. Many reports that deeper mathematical understanding is unlikely to achieve without practicing other pedagogical aspects in the classroom. Without 
careful consideration, a game may fail students to acquire mathematical skills (Pujiastuti \& Fitriah, 2019).

Generally, the game offers new variety to engage students in or outside the classroom. However, the game is not one-size-fits-all. There are many factors to consider before teachers decide to use the game in mathematics classrooms, such as students' motivation. Additionally, no matter how fun a game is, one will eventually be bored doing the same activities multiple times. Therefore, the game should only be considered one of the varied learning activities to support learning activity.

\section{CONCLUSION}

Based on the results and discussion above, mathematics teaching materials based on scientific approaches can be used in learning mathematics to improve the ability of mathematical concepts. That mathematics teaching material based on a scientific method has good feasibility and content to be used by junior high school.

\section{REFERENCES}

Chakraborty, U. K. (2008). Genetic And Evolutionary Computing. Information Sciences, 178(23), 4419-4420.

https://doi.org/10.1016/j.ins.2008.0 7.026

Fan, K., \& Xiao, P. (2015). The Effects of Learning Styles and Meaningful Learning on the Learning Achievement of Gamification Health Education Curriculum. Eurasia Journal of Mathematics, Science \& Technology Education, 11(59), 1211-1229. https://doi.org/10.12973/eurasia.20 $15.1413 \mathrm{a}$
Humienny, Z., \& Berta, M. (2015). A Digital Application For Geometrical Tolerancing Concepts Understanding. Procedia CIRP, 27, 264-269. https://doi.org/10.1016/j.procir.201 5.04.076

Laar, E. Van, Deursen, A. J. A. M. Van, Dijk, J. A. G. M. Van, \& Haan, J. De. (2017). Computers In Human Behavior The Relation Between 21st-Century Skills and Digital Skills: A Systematic Literature review. Computers in Human Behavior, 72, 577-588. https://doi.org/10.1016/j.chb.2017. 03.010

Lee, C. (2017). Evaluating Game-Brand Congruity and Flow on Brand Personality by Using Gamifying Learning. Eurasia Journal of Mathematics, Science \& Technology Education, 8223(7), 3083-3097.

https://doi.org/10.12973/eurasia.20 $17.00706 \mathrm{a}$

Lin, H. S. (2017). Effects of Comparison and Game-Challenge on Sixth Graders' Algebra Variable Learning Achievement, Learning Attitude, and Meta-Cognitive Awareness. Eurasia Journal of Mathematics, Science \& Technology Education, 8223(6), 2627-2644. https://doi.org/10.12973/eurasia.20 $17.01244 \mathrm{a}$

Lubis, A. H. (2018). ICT Integration In 21st-Century Indonesian English Language Teachingmyths and Realities. Cakrawala Pendidikan, 37(1), 11-21. https://doi.org/10.21831/cp.v37i1.1 6738 
DOI: https://doi.org/10.24127/ajpm.v9i3.2902

Mason, J. (2019). Relationships Between Proof and Examples: Comments Arising from The Papers In This Issue. Journal of Mathematical Behavior, 53(August 2017), 339-347. https://doi.org/10.1016/j.jmathb.20 17.07.005

Mcgrath, J., \& Fischetti, J. (2019). What If Compulsory Schooling Was A 21 st Century Invention? Weak Signals From A Systematic Review of The Literature. International Journal of Educational Research, 95(April), 212-226.

https://doi.org/10.1016/j.ijer.2019. 02.006

Meredith D. Gall, Walter R. Borg, J. P. G. (2003). Educational Research: An Introduction (7th Edition) (p. 683). p. 683. https://doi.org/0321081897,978032 1081896

Psycharis, S., \& Kotzampasaki, E. (2019). The Impact Of A Stem Inquiry Game Learning Scenario On Computational Thinking And Computer Self-Confidence. Eurasia Journal of Mathematics, Science and Technology Education, 15(4). https://doi.org/10.29333/ejmste/10 3071

Pujiastuti, H., \& Fitriah, F. (2019). Design of Interactive Teaching Materials Based on A Scientific Approach To Support Junior High School Students' Learning: Line and Angles. Journal of Physics: Conference Series, 1157(3). https://doi.org/10.1088/17426596/1157/3/032087
Pujiastuti, Heni, Ayatullah, F., \& Haryadi, R. (2019). The Influence of Inquiry Learning Model towards Students' Mathematical Critical Thinking Ability. Unnes Journal Of Mathematics Education, 8(3), 216-223.

https://doi.org/10.15294/ujme.

Pujiastuti, Heni, \& Haryadi, R. (2020). The Use of Augmented Reality Blended Learning for Improving Understanding of Food Security in Universitas Sultan Ageng Tirtayasa: A Case Study. Jurnal Pendidikan IPA Indonesia T, 9(1). https://doi.org/10.15294/jpii.v9i1.2 1742

Pujiastuti, Heni, Suvanti, D., Haryadi, R., \& Marethi, I. (2020). Development of Maths module Based on Local Wisdom And $21 \mathrm{St}$ Century Skills: Linear Equation System. Journal of Physics: Conference Series. https://doi.org/10.1088/17426596/1480/1/012052

Pujiastuti, Heni, Utami, R., \& Haryadi, R. (2020). The Development of Interactive Mathematics Learning Media Based on Local Wisdom And 21st Century Skills: Social Arithmetic Concept. Journal of Physics: Conference Series. https://doi.org/10.1088/17426596/1521/3/032019

Saritepeci, M. (2019). Developing Computational Thinking Skills of High School Students: DesignBased Learning Activities and Programming Tasks. The AsiaPacific Education Researcher. https://doi.org/10.1007/s40299019-00480-2 
DOI: https://doi.org/10.24127/ajpm.v9i3.2902

Shepherd, M. D., \& van de Sande, C. C. (2014). Reading Mathematics For Understanding-From Novice To Expert. Journal of Mathematical Behavior, 35, 74-86. https://doi.org/10.1016/j.jmathb.20 14.06.003

Simon, M. A. (2018). An Emerging Methodology for Studying Mathematics Concept Learning and Instructional Design. Journal of Mathematical Behavior, 52(March), 113-121. https://doi.org/10.1016/j.jmathb.20 18.03.005

Simonova, I., \& Poulova, P. (2017). Learners Preferences in MobileAssisted Higher Education. Procedia - Procedia Computer Science, 104(December 2016), 174-182.

https://doi.org/10.1016/j.procs.201 7.01 .099

Soboleva, E. V, Galimova, E. G., \& Maydangalieva, Z. A. (2018). Didactic Value of Gamification Tools for Teaching Modeling as a Method of Learning and Cognitive Activity at School. Eurasia Journal of Mathematics, Science \& Technology Education, 14(6), 2427-2444.

Solomon, Y., \& Croft, T. (2015). Understanding undergraduate disengagement from mathematics: Addressing alienation. International Journal of Educational Research, 79, 267276. https://doi.org/10.1016/j.ijer.2015. 10.006
Sriklaub, K., \& Wongwanich, S. (2014). Learning Activities Aimed at Promoting Students' Interest: Synthesis of Master Teachers' Activity Organizing Methods via TV Media. Procedia - Social and Behavioral Sciences, 116, 33753380.

https://doi.org/10.1016/j.sbspro.20 14.01.767

Su, C. (2017). The Effects of Students' Learning Anxiety and Motivation on the Learning Achievement in the Activity Theory Based Gamified Learning Environment. Eurasia Journal of Mathematics, Science \& Technology Education, 8223(59), 1229-1258. https://doi.org/10.12973/eurasia.20 $17.00669 \mathrm{a}$

Su, C., \& Hsaio, K. (2015). Developing and Evaluating Gamifying Learning System by Using FlowBased Model. Eurasia Journal of Mathematics, Science \& Technology Education, 11(59), 1283-1306.

https://doi.org/10.12973/eurasia.20 $15.1386 \mathrm{a}$

Te Pas, E., Waard, M. W. De, De Ruijter, W., \& Van Dijk, N. (2015). Learning Results of GP Trainers in A Blended Learning Course on EBM: A Cohort Study Career Choice, Professional Education, And Development. BMC Medical Education, 15(1). https://doi.org/10.1186/s12909015-0386-2 
DOI: https://doi.org/10.24127/ajpm.v9i3.2902

Teng, Y., Wang, Y., Wang, J., \& Zhang, L. (2017). Research on Decision-making Behavior Evolution of Government, Coal Mine Enterprises, and Employees under Safe Education. Eurasia Journal of Mathematics, Science \& Technology Education, 8223(12), 8267-8281. https://doi.org/10.12973/ejmste/80 788

Wessman-enzinger, N. M. (2019). Grade 5 Children's Drawings for Integer Addition and Subtraction Open Number Sentences. Journal of Mathematical Behavior, 53(July 2018), 105-128. https://doi.org/10.1016/j.jmathb.20 18.03.010
Zaslavsky, O. (2019). There Is More To Examples Than Meets The Eye: Thinking With and Through Mathematical Examples in Different Settings. Journal of Mathematical Behavior, 53(October 2017), 245-255. https://doi.org/10.1016/j.jmathb.20 17.10.001

Zuin, M., Rigatelli, G., Faggian, G., \& Roncon, L. (2018). Mathematics and Thrombolysis: Role of The Mathematical Modelling in Understanding and Developing Blood Clot Fragmentation. European Journal of Internal Medicine, 54(June), e19-e20. https://doi.org/10.1016/j.ejim.2018 .06 .003 